\title{
DESINFECCIÓN DEL EFLUENTE SECUNDARIO DE LA PLANTA DE AGUA RESIDUAL DE AYACUCHO CON RADIACIÓN ULTRAVIOLETA PARA SU REUTILIZACIÓN EN RIEGO AGRÍCOLA
}

\author{
Raúl Ricardo Véliz Flores ${ }^{* a}$, Edgar Gregorio Aronés Medina ${ }^{a}$, \\ Ybar Gustavo Palomino Malpartida ${ }^{\mathrm{a}}$, Rudecindo Huincho Rodríguez
}

\begin{abstract}
RESUMEN
El agua del efluente secundario de la planta de tratamiento de agua residual Totora de Ayacucho desinfectada con cloro, vertida al río Alameda no tiene la calidad sanitaria en cuanto a microrganismos patógenos para riego agrícola; sin embargo, es reutilizada en el cultivo de verduras que se comercializan en la ciudad de Ayacucho, problema que motivó la investigación para utilizar otro método de desinfección. Las pruebas experimentales se realizaron con muestras del efluente secundario, se utilizó la desinfección con radiación ultravioleta para la desactivación y eliminación de microorganismos patógenos. Se realizaron dos tipos de pruebas experimentales a nivel de laboratorio para la desinfección ultravioleta, primero con agua del efluente secundario de la planta, tal como ingresa a la laguna de cloración y segundo realizando dos operaciones de tratamiento antes de la desinfección ultravioleta, una de filtración y otra de adsorción. Los ensayos con la primera prueba experimental de desinfección ultravioleta, presentaron poca eficiencia en cuanto a la remoción de microorganismos (20 $323 \mathrm{NMP} / 100 \mathrm{ml})$, no alcanzando la calidad sanitaria para riego de vegetales no restringidos y restringidos, según los límites máximos permisibles de la norma peruana (DS-004-2017-MINAM)2, en cambio, con la segunda prueba, se mejoró notablemente la eficiencia de la desinfección y reducción de microorganismos patógenos (949 NMP/100 ml), concluyendo que con este método se obtuvo agua de buena calidad sanitaria y que puede ser reutilizada en riego de vegetales.
\end{abstract}

Palabras clave: Desinfección UV, PTAR, microorganismos patógenos, Ayacucho.

\footnotetext{
a Facultad de Ingeniería Química y Metalurgia, Universidad Nacional de San Cristóbal de Huamanga, Los Portales N57, Ayacucho 51, Perú, rau10348@yahoo.es

${ }^{\mathrm{b}}$ Planta de Tratamiento de Agua Residual Totora de Ayacucho
} 


\title{
DISINFECTION OF SECONDARY EFFLUENT FROM WASTE WATER PLANT IN AYACUCHO BY UV RADIATION FOR AGRICULTURAL IRRIGATION REUSE
}

\begin{abstract}
The water of the secondary effluent of the wastewater treatment plant Totora in Ayacucho disinfected with chlorine, discharged into the Alameda River, does not have the sanitary quality in terms of pathogenic microorganisms for agricultural irrigation, however, it is reused in the cultivation of vegetables. they commercialize in the city of Ayacucho, problem that motivated the investigation to use another method of disinfection. Experimental tests were carried out with samples of the secondary, by using ultraviolet disinfection for deactivation and elimination of pathogenic microorganisms. Two types of laboratory scale experimental tests were performed for ultraviolet disinfection, first with water from the secondary effluent plant, as it enters the chlorination lagoon and secondly performing two treatment operations before ultraviolet disinfection, filtration and adsorption. The first experimental test showed little efficiency in the removal of microorganisms (20 323 NMP / $100 \mathrm{ml}$ ), not reaching sanitary quality for irrigation with unrestricted and restricted, according to the maximum allowable limits of the Peruvian standard (DS-004-2017-MINAM),2 in contrast with the second test the disinfection efficiency and pathogenic microorganisms reduction (949 NMP / $100 \mathrm{ml}$ ) were significantly improved, concluding that with this method water of good sanitary quality was obtained and can be reused in vegetables irrigation.
\end{abstract}

Key words: UV disinfection, WWTP, pathogenic microorganisms, Ayacucho.

\section{INTRODUCCIÓN}

El efluente secundario de la Planta de Tratamiento de Agua Residual (PTAR) Totora, desinfectada con cloro y vertida al río Alameda de Ayacucho, no tiene la calidad sanitaria para riego de vegetales, en cuanto a microorganismo patógenos ${ }^{1}$. El efluente de la planta Totora, vertió el 30 de setiembre del año 2015 al río Alameda: $61,3 \mathrm{mg} / 1$ de demanda bioquímica de oxígeno $\left(\mathrm{DBO}_{5}\right), 2,8 \times 10^{4}$ número más probable $(\mathrm{NMP}) / 100 \mathrm{ml}$ de coliformes fecales y 33 $\mathrm{mg} / \mathrm{l}$ de sólidos totales en suspensión (STS), parámetros distantes de la norma peruana según el D.S. No 004-2017-MINAM ${ }^{2}$ que indica que los estándares ambientales de calidad del agua para riego de vegetales no restringido y restringido son: $15 \mathrm{mg} / \mathrm{l}$ para la $\mathrm{DBO}_{5}, 1000$ y 2000 $\mathrm{NMP} / 100 \mathrm{ml}$ para coliformes fecales.

Para reutilizar agua para riego de vegetales, estos dependen del tipo de riego empleado en los cultivos, la forma de consumo de los vegetales crudo o cocido y de los procesos a los cuales son sometidos los productos agrícolas. El DS 004-2017-MINAM ${ }^{2}$ presenta los LMP para el agua de riego de vegetales no restringidos y restringidos, siendo de mayor importancia la 
primera por la utilización del agua en riego de: cultivos alimenticios que se consumen crudos y en la segunda la utilización del agua en riego de cultivos alimenticios que se consumen cocidos.

Los cultivos de verduras en los valles de los ríos Alameda y Chacco en Ayacucho son regados, en parte, con agua del efluente de la PTAR Totora, que al ser comercializadas en los mercados de la ciudad producen al consumidor enfermedades originadas por el agua producida por microrganismos patógenos, problema latente que requiere solución y que fue motivo de la investigación.

Se evaluaron algunas alternativas de solución utilizando nuevos métodos de tratamientos terciarios, como las operaciones unitarias de filtración y adsorción antes de una desinfección con radiación ultravioleta (UV), por presentar varias ventajas como lo afirma Pietroban ${ }^{3}$, proceso físico que no deja residuos químicos, no altera el sabor, el olor y la composición química del agua. La radiación UV es actualmente una de las mejores alternativas de desinfección del agua residual y potable, tanto en los países de Europa y América del Norte, toda vez que el sistema tradicional de desinfección por cloro produce subproductos peligrosos tales como las cloraminas, los trihalometanos y otros compuestos orgánicos clorados que afectan la salud humana y al medio ambiente ${ }^{4}$.

El objetivo principal de la investigación fue realizar pruebas experimentales de desinfección UV del efluente secundario de la planta Totora, utilizando un sistema hidráulico y un reactor piloto de radiación UV, mediante dos procesos de desinfección UV, primero con el efluente secundario tal como se obtiene en la planta Totora y segundo utilizando dos procesos terciarios de tratamiento antes de la desinfección UV. Finalmente, se evaluó si existe algún grado de mejoramiento en la calidad de agua para riego de vegetales no restringido y restringido, en cuanto a la reducción de microorganismos patógenos cuando se aplica la desinfección UV frente a la desinfección con cloro.

\section{PARTE EXPERIMENTAL}

Los experimentos se realizaron con muestras del efluente secundario de la PTAR Totora de Ayacucho, tomadas antes de la laguna de cloración (LC), figura 1a.

\section{Reactor UV}

Cuando se diseña un proceso de desinfección con radiación UV, el diseño está estrechamente relacionado con el equipo hidráulico y el reactor de radiación UV. La tabla 1 presenta las características y especificaciones del equipo piloto de radiación UV. 
Tabla 1. Características y especificaciones técnicas del reactor UV.

\begin{tabular}{lc}
\hline \multicolumn{1}{c}{ Características } & Especificaciones \\
\hline Potencia nominal & $17 \mathrm{~W}$ \\
Intensidad de la corriente eléctrica & $0,3 \mathrm{~A}$ \\
Vida media de funcionamiento & 9000 horas \\
Diámetro externo de la lámpara & $26 \mathrm{~mm}$ \\
Diámetro interno del reactor & $63 \mathrm{~mm}$ \\
Longitud de la lámpara & $30 \mathrm{~cm}$ \\
Presión de la lámpara & Baja \\
\hline
\end{tabular}

\section{Variables analizadas y métodos analíticos utilizados}

La tabla 2 presenta las variables analizadas y los métodos analíticos utilizados en los análisis fisicoquímico y bacteriológico de muestras del efluente secundario antes y después de la desinfección UV.

Tabla 2. Variables y métodos utilizados en la caracterización del efluente secundario.

\begin{tabular}{ll}
\hline Variables y unidades & \multicolumn{1}{c}{ Método o equipo utilizado } \\
\hline Absorbancia a $254 \mathrm{~nm},\left[\mathrm{~m}^{-1}\right]$ & Espectrofotométrico \\
Coliformes fecales, $[\mathrm{NMP} / 100 \mathrm{ml}]$ & Tubos múltiples \\
Conductividad, $[\mu \mathrm{S} / \mathrm{cm}]$ & Lectura automática en un conductímetro \\
$\mathrm{DBO}_{5},\left[\mathrm{mg} \mathrm{O}_{2}\right.$ disuelto $\left./ 1\right]$ & Respirométrico \\
$\mathrm{pH},[\mathrm{unidades}$ de $\mathrm{pH}]$ & pHmetro \\
$\mathrm{STS},[\mathrm{mg} / 1]$ & Gravimétrico, filtrado a $0,45 \mu \mathrm{m}$ y $102^{\circ} \mathrm{C}$ \\
Temperatura, $\left[{ }^{\circ} \mathrm{C}\right]$ & Lectura automática en un termómetro $\mathrm{Hg}$ \\
Turbidez, $[\mathrm{UTN}]$ & Lectura automática en un turbidímetro \\
\hline
\end{tabular}

\section{Equipo hidráulico y unidad piloto de desinfección UV}

El sistema hidráulico y la unidad piloto de desinfección UV, figura 1c, consta de un tanque de almacenamiento de 50 litros, una bomba centrífuga de 1/4 hp para la impulsión del agua, un filtro para retener sedimentos mayores de 3 micras, un adsorbedor de carbón activado para retener partículas, iones y purificar, desodorizar y decolorar el agua, y un reactor de desinfección UV.

El sistema de transporte tanque-bomba-reactor está unido por tuberías de PVC de 1/2 pulgada. La carcasa del reactor es de acero inoxidable, el flujo de agua circula en dirección paralela a una lámpara inmersa que contiene vapor de $\mathrm{Hg}$ a baja presión, la lámpara está protegida por un tubo de cuarzo y produce radiación UV en la longitud de onda de 253,7 nm (nanómetro), energía que es absorbida por los ácidos nucleicos de los microorganismos, inactivándolos o causándoles la muerte. 
(a)

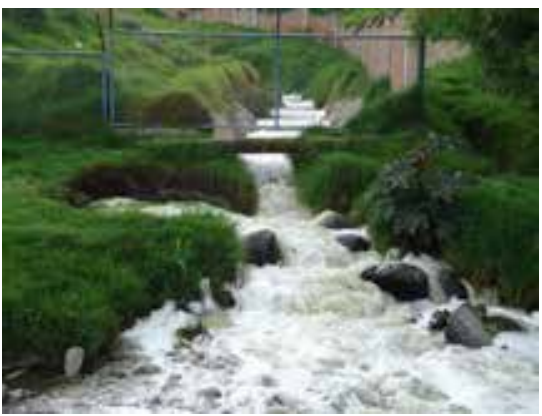

(b)
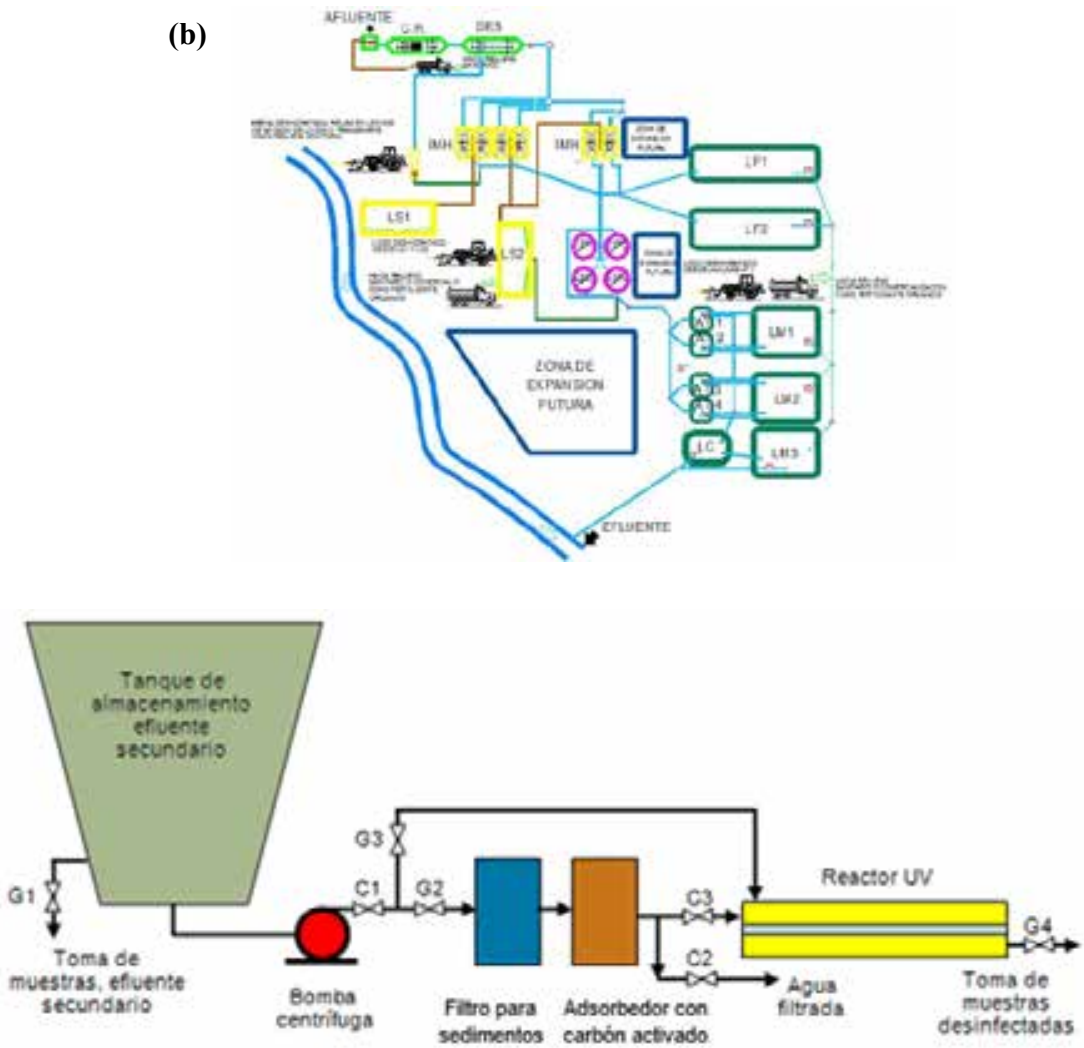

Figura 1. (a) Esquema de la PTAR Totora-Ayacucho. (b) Foto (12-05-16), vertido de agua del efluente secundario PTAR Totora al río Alameda. (c) Esquema de la unidad piloto de desinfección UV. 


\section{Equipo hidráulico y unidad piloto de desinfección UV}

El sistema hidráulico y la unidad piloto de desinfección UV, figura 1c, consta de un tanque de almacenamiento de 50 litros, una bomba centrífuga de 1/4 hp para la impulsión del agua, un filtro para retener sedimentos mayores de 3 micras, un adsorbedor de carbón activado para retener partículas, iones y purificar, desodorizar y decolorar el agua, y un reactor de desinfección UV.

El sistema de transporte tanque-bomba-reactor está unido por tuberías de PVC de 1/2 pulgada. La carcasa del reactor es de acero inoxidable, el flujo de agua circula en dirección paralela a una lámpara inmersa que contiene vapor de $\mathrm{Hg}$ a baja presión, la lámpara está protegida por un tubo de cuarzo y produce radiación UV en la longitud de onda de 253,7 nm (nanómetro), energía que es absorbida por los ácidos nucleicos de los microorganismos, inactivándolos o causándoles la muerte.

\section{Tiempo de retención hidráulica, TRH}

El tiempo de retención hidráulica se define como el tiempo que permanece el agua en el reactor de radiación UV, que fluye con flujo continuo. El TRH es igual al volumen del reactor dividido por el caudal promedio.

Procedimiento: Se fijó un volumen de descarga de 6 litros en el tanque de almacenamiento para las pruebas de los tiempos promedios de descarga. En el tanque de almacenamiento internamente se marcó tres líneas que sirvieron para controlar el flujo de descarga, la primera línea fue marcada tomando como base la superficie libre del agua (parte superior del tanque), esta indica el inicio de la cantidad de fluido que se debe descargar para alcanzar el estado estable, la segunda línea marcada indica el inicio de descarga del volumen de 6 , aquí se activa el cronómetro, tomando el tiempo como tiempo igual a cero, la tercera línea marcada indica el final de descarga de los 6 litros, aquí se detiene el cronómetro y se lee el tiempo transcurrido. La variación del flujo del fluido de descarga se realizó manipulando el vástago de la válvula de globo G3, que controla el flujo de salida de la bomba.

\section{Metodología experimental para el proceso de desinfección UV}

Los parámetros hidráulicos de funcionamiento y operación del reactor UV más importantes fueron monitoreados, los tiempos de residencia y caudales fueron controlados y variados mediante la manipulación del vástago de la válvula de control, los demás parámetros fueron fijados por la geometría del sistema buscando la mejor eficiencia de la desinfección. Se realizaron dos tipos de ensayos de desinfección UV:

\section{Ensayos tipo 1}

Efluente secundario de la PTAR Totora.

Proceso de desinfección UV: tanque-bomba-reactor UV. 


\section{Ensayos tipo 2:}

Efluente secundario de la PTAR Totora.

Procesos previos: tanque-equipo de filtración-equipo de absorción de carbón activado.

Proceso desinfección UV: tanque-bomba-reactor UV.

\section{RESULTADOS Y DISCUSIÓN}

\section{Tiempo y caudal promedio}

La última columna de resultados en la tabla 3 muestra los caudales promedios para seis aperturas de la válvula de control de flujo, estos fueron obtenidos dividiendo el volumen de 6 litros entre los tiempos promedios de cada ensayo.

Tabla 3. Tiempos promedios y caudales para un volumen de 6 litros de descarga.

\begin{tabular}{|c|c|c|c|c|c|c|c|}
\hline \multirow[b]{2}{*}{$\begin{array}{l}\text { Giro del vástago } \\
\text { válvula de control }\end{array}$} & \multicolumn{5}{|c|}{ Tiempos, [s] } & \multirow{2}{*}{$\begin{array}{c}\text { Tiempo } \\
\text { promedio } \\
t_{\mathrm{P}},[\mathrm{s}]\end{array}$} & \multirow{2}{*}{$\begin{array}{c}\text { Caudal } \\
\text { promedio } \\
Q_{P},[1 / \mathrm{s}]\end{array}$} \\
\hline & $t_{1}$ & $\mathrm{t}_{2}$ & $t_{3}$ & $\mathrm{t}_{4}$ & $t_{5}$ & & \\
\hline Totalmente abierta & 8,01 & 7,69 & 7,90 & 7,77 & 7,73 & 7,82 & 0,7673 \\
\hline $1 / 4$ vuelta cerrada & 11,36 & 11,47 & 11,32 & 11,02 & 11,53 & 11,34 & 0,5291 \\
\hline $1 / 2$ vuelta cerrada & 14,98 & 14.68 & 15,35 & 14,81 & 15,03 & 14,97 & 0,4008 \\
\hline $3 / 4$ vuelta cerrada & 18,35 & 18,66 & 18,02 & 18,71 & 18,16 & 18,38 & 0,3265 \\
\hline 1 vuelta cerrada & 21,89 & 22,15 & 22,01 & 21,70 & 22,20 & 21,99 & 0,2728 \\
\hline $11 / 2$ vuelta cerrada & 25,94 & 25,57 & 25,75 & 25,14 & 25,50 & 25,58 & 0,2346 \\
\hline
\end{tabular}

\section{Tiempo de retención hidráulica, TRH}

La tabla 4 muestra los TRH y los modelos de flujo a medida que se cierra la válvula de control. Los cuatro primeros ensayos presentan flujos turbulentos (estados estables), los dos últimos flujos en transición (estados inestables) y si se continúa cerrando la válvula se debe llegar a flujos laminar (estados estables). Estos resultados demuestran que se debe buscar ensayos con el mejor y menor TRH con flujos estables de acuerdo al modelo de flujo real que se presenta en el efluente de la PTAR Totora. 
Tabla 4. Tiempo de retención hidráulica (TRH) y modelo de flujo.

\begin{tabular}{lcccc}
\hline $\begin{array}{l}\text { Giro vástago de la } \\
\text { válvula de control }\end{array}$ & $\begin{array}{c}\text { Caudal } \\
\text { promedio } \\
\mathrm{Q}_{\mathrm{P},[1 / \mathrm{s}]}\end{array}$ & $\begin{array}{c}\mathrm{TRH},[\mathrm{s}] \\
\mathrm{TRH}= \\
\mathrm{V}_{\text {reactor }} / \mathrm{Q}_{\mathrm{P}}\end{array}$ & $\begin{array}{c}\text { Número de } \\
\text { Reynolds }\end{array}$ & $\begin{array}{c}\text { Modelo de } \\
\text { flujo }\end{array}$ \\
\hline Totalmente abierta & 0,7673 & 1,011 & 10063 & Turbulento \\
$1 / 4$ vuelta cerrada & 0,5291 & 1,467 & 6960 & Turbulento \\
$1 / 2$ vuelta cerrada & 0,4008 & 1,936 & 5249 & Turbulento \\
$3 / 4$ vuelta cerrada & 0,3265 & 2,377 & 4292 & Turbulento \\
1 vuelta cerrada & 0,2728 & 2,845 & 3596 & Transición \\
1 1/2 vuelta cerrada & 0,2346 & 3,308 & 3074 & Transición \\
\hline
\end{tabular}

Volumen del reactor

$$
\begin{aligned}
V_{\text {reactor }} & =V_{\text {Total }}-V_{\text {lámpara }} \\
V_{\text {reactor }} & =\frac{\pi}{4} 6,3^{2} \times 30-\frac{\pi}{4} 2,6^{2} \times 30 \\
V_{\text {reactor }} & =775,89 \mathrm{~cm}^{3}=0,77589 \mathrm{l}
\end{aligned}
$$

En diseño de equipos y diseño de procesos se trabaja con estados estables y como en los dos últimos ensayos para la determinación de los TRH se presentó dos flujos en transición con estados inestables, estos ensayos fueron observados y no se tomaron en cuenta en la continuación de la investigación. Los resultados muestran que los TRH están comprendidos entre 1,011 a 2,377 s, asegurando flujos turbulentos y continuos para el proceso de desinfección UV, donde el agua debe permanecer dentro del reactor durante un tiempo igual a los TRH, tiempo de exposición, inactivación y eliminación de microorganismos (bacterias, virus, protozoos, helmintos y nematodos intestinales) dentro del reactor. Los TRH obtenidos guardan relación con el trabajo de investigación por Divino ${ }^{5}$, que utiliza un reactor de radiación UV, para desinfectar piscinas de hidroterapia.

\section{Proceso de desinfección UV (30-09-15): ensayo tipo 1}

Análisis fisicoquímico: La tabla 5 muestra los resultados de los análisis físico-químicos del efluente secundario antes y después de la desinfección UV, ensayo tipo 1.

Tabla 5. Análisis fisicoquímico del efluente secundario, ensayo tipo 1.

\begin{tabular}{lcc}
\hline \multicolumn{1}{c}{ Parámetro } & $\begin{array}{c}\text { Fluido del efluente } \\
\text { secundario PTAR Totora }\end{array}$ & $\begin{array}{c}\text { Fluido después del proceso } \\
\text { de desinfección UV }\end{array}$ \\
\hline Absorbancia, $\left[\mathrm{cm}^{-1}\right]$ & 0,408 & 0,405 \\
Conductividad, $[\mu \mathrm{S} / \mathrm{cm}]$ & 567,1 & 565,7 \\
$\mathrm{DBO}_{5},\left[\mathrm{mg} \mathrm{de} \mathrm{O}_{2} / 1\right]$ & 59,5 & 58,6 \\
$\mathrm{pH},[\mathrm{unidades} \mathrm{de} \mathrm{pH}]$ & 7,59 & 7,48 \\
$\mathrm{STS},[\mathrm{mg} / \mathrm{l}]$ & 36 & 35 \\
Temperatura, $\left[{ }^{\circ} \mathrm{C}\right]$ & 21,8 & 21,9 \\
Turbiedad, $[\mathrm{UNT}]$ & 24,7 & 24,2 \\
\hline
\end{tabular}


Los resultados de la tabla 5 muestra que los parámetros fisicoquímicos analizados no fueron afectados significativamente por la desinfección UV, y no se ha producido ninguna reacción química, afirmación que está de acuerdo con lo que concluye $\operatorname{Vargas}^{6}$, que la radiación UV ha sido ampliamente estudiada como método de desinfección de aguas por presentar una gran ventaja sobre la desinfección por cloro debido a que no deja subproductos tóxicos.

Análisis bacteriológico: La tabla 6 contiene los resultados de los TRH con flujos turbulentos estables en función de la cantidad de coliformes fecales (CF), antes y después de la desinfección UV, tipo de ensayo 1 y el porcentaje de remoción de microorganismos patógenos. El porcentaje de remoción de microorganismos que presenta la última columna de la tabla 6 está comprendida entre 73,83 a 80,43\%, rendimientos bajos, esto se debe a que el efluente secundario contiene mucho cantidad de sólidos en suspensión y una alta turbidez, premisa que está de acuerdo con Vargas ${ }^{6}$ que indica que la radiación UV tiene algunas limitaciones para su uso que afectan la eficiencia, tales como la presencia de sólidos en suspensión de componentes coloidales y material particulado en el agua, ya que estos materiales sirven como protección a los microorganismos de la radiación UV.

Como la eficiencia de remoción de microrganismos del ensayo tipo 1 presenta valores bajos, para mejorar el proceso es necesario realizar un post tratamiento terciario (filtración y absorción) antes de la desinfección UV, a fin de reducir los sólidos en suspensión y la turbidez del efluente secundario.

Tabla 6. Coliformes fecales antes y después de la desinfección UV, ensayo tipo 1, porcentaje de remoción.

\begin{tabular}{cccc}
\hline TRH, $[\mathrm{s}]$ & $\begin{array}{c}\text { No, }[\mathrm{NMP} / 100 \mathrm{ml}] \\
\text { CF iniciales }\end{array}$ & $\begin{array}{c}\text { N, }[\mathrm{NMP} / 100 \mathrm{ml}] \\
\text { CF sobrevivientes }\end{array}$ & $\begin{array}{c}\text { Remoción } \\
\%\end{array}$ \\
\hline 1,011 & 212328 & 55591 & 73,82 \\
1,467 & 212328 & 38548 & 81,85 \\
1,936 & 212328 & 27797 & 86,91 \\
2,377 & 212328 & 20323 & 90,43
\end{tabular}

Finalmente, para el ensayo tipo 1 desinfección UV, se concluye que con este método no se puede alcanzar la calidad sanitaria del agua para riego no restringido y restringido, porque no se aproxima a los LMP del DS-004-2014-MINAM2 (1000 y 2000 NMP/100 ml), debido a que se obtuvo en la desinfección 20323 MNP de coliformes fecales sobrevivientes en 100 $\mathrm{ml}$ agua.

\section{Proceso de desinfección UV (30-09-15), ensayo tipo 2}

Análisis fisicoquímico: La tabla 7 muestra los resultados de los análisis fisicoquímicos del efluente secundario, antes y después del tratamiento previo del agua mediante procesos de filtración y adsorción, para luego realizar la desinfección UV. 
Tabla 7. Análisis fisicoquímico del efluente secundario ensayo tipo 2

\begin{tabular}{lcc}
\hline \multicolumn{1}{c}{ Parámetro } & Efluente secundario & $\begin{array}{c}\text { Efluente después del } \\
\text { filtrado y adsorción }\end{array}$ \\
\hline Absorbancia, $\left[\mathrm{cm}^{-1}\right]$ & 0,408 & 0,284 \\
Conductividad, $[\mu \mathrm{S} / \mathrm{cm}]_{\mathrm{DBO}},\left[{\left.\mathrm{mg} \mathrm{de} \mathrm{O}_{2} / \mathrm{l}\right]}_{\mathrm{pH},[\text { unidades de } \mathrm{pH}]}^{567,1}\right.$ & 375,5 \\
$\mathrm{STS},[\mathrm{mg} / \mathrm{l}]$ & 59,5 & 17,2 \\
Temperatura, $\left[{ }^{\circ} \mathrm{C}\right]$ & 7,59 & 7,68 \\
Turbiedad, $[\mathrm{UNT}]$ & 36,0 & 10,0 \\
& 21,8 & 21,6 \\
\hline
\end{tabular}

En la tabla 7 se observa la disminución de los valores de los parámetros: $\mathrm{DBO}_{5}$, STS y turbiedad, valores después del tratamiento previo mediante procesos de filtración y adsorción. La disminución de la concentración de los STS de 36 a 10 mg/l es muy importante porque favorece a la desinfección UV, tal como afirma Dos Santos ${ }^{7}$ que la radiación UV inactiva con mejor eficiencia a los microorganismos, cuando la concentración de STS es preferentemente inferior a $10 \mathrm{mg} / \mathrm{l}$.

La Agencia de Protección Ambiental de Estados Unidos (EPA $)^{8}$, informa que la temperatura del agua tiene poca o ninguna influencia en la eficiencia de la desinfección con radiación ultravioleta y la turbiedad debe ser tan baja como sea posible, en todo caso deben evitarse turbiedades mayores a 5 UNT, en la tabla 7 se observa que luego del tratamiento previo la turbiedad decrece de 24,7 a 5,4 UNT, valor que indica que se puede alcanzar una buena desinfección UV.

Vargas $^{6}$ llega a la conclusión de que el proceso de tratamiento de filtración y la adsorción con carbón activado, son técnicas promisoras debido a que se obtienen efluentes de alta calidad, alta capacidad de remoción de contaminantes estables y por su viabilidad económica, cuando se compara con otras metodologías de tratamiento terciario del agua.

Análisis bacteriológico: La tabla 8 contiene en la primera columna los TRH, en la segunda columna los microorganismos sobrevivientes luego del tratamiento previo de filtración y adsorción, en la tercera columna los microorganismos sobrevivientes al proceso de desinfección UV tipo de ensayo 2, en la cuarta columna el porcentaje de microorganismos removidos y en la quinta columna los valores de la relación $-\log \left(\mathrm{N} / \mathrm{N}_{0}\right)$. 
Tabla 8. Coliformes fecales antes y después de la desinfección UV ensayo tipo 2, porcentaje de remoción.

\begin{tabular}{ccccc}
\hline \multirow{2}{*}{ TRH, [s] } & No, & N, & \multicolumn{2}{c}{ Remoción } \\
\cline { 5 - 5 } & $\begin{array}{c}\text { [NMP } / 100 \mathrm{ml}] \\
\text { CF iniciales }\end{array}$ & $\begin{array}{c}\text { [NMP/ } / 100 \mathrm{ml}] \\
\text { CF sobrevivientes }\end{array}$ & $\%$ & $-\log (\mathrm{N} / \mathrm{No})$ \\
\hline 1,011 & 190194 & 5862 & 96,92 & 1,511 \\
1,467 & 190194 & 2776 & 98,54 & 1,836 \\
1,936 & 190194 & 1517 & 99,20 & 2,098 \\
2,377 & 190194 & 949 & 99,50 & 2,302 \\
\hline
\end{tabular}

En cuanto a la remoción de microrganismo patógenos con este método se mejoró notablemente la eficiencia alcanzando $99,50 \%$ para un TRH de 2,377 s y $949 \mathrm{NMP} / 100 \mathrm{ml}$ de microorganismos patógenos sobrevivientes.

TRH de inactivación de coliformes fecales: El modelo matemático de la ley de Chick permite calcular los TRH de eliminación de CF para una inactivación total de microorganismos, 1000 y $2000 \mathrm{NMP} / 100 \mathrm{ml}$ de coliformes fecales sobrevivientes, valores LMP en la reutilización de agua categoría 3, riego de vegetales no restringido y restringido.

$$
\begin{aligned}
& \begin{array}{l}
\text { Ley de } \text { Chick }^{9} \\
\frac{\mathrm{N}}{\mathrm{N}_{0}}=\mathrm{e}^{-\mathrm{kt}}
\end{array} \\
& \begin{array}{l}
\mathrm{k}=\text { constante de velocidad de reacción o de decaimiento, } \\
{\left[\mathrm{s}^{-1}\right]}
\end{array} \\
& \left.\begin{array}{l}
\mathrm{N}=\text { concentración de microorganismos, [NMP/ } 100 \mathrm{ml}] \\
N_{0}
\end{array}\right)=\frac{k}{2,302585} t \begin{array}{l}
\mathrm{t}=\text { tiempo de retención hidráulica, [s] }
\end{array}
\end{aligned}
$$

La ecuación de Chick integrada presenta la ecuación de una línea recta, entonces al graficar en abscisas $-\log (\mathrm{N} / \mathrm{N} 0)$ y en ordenadas $\operatorname{los} \mathrm{TRH}(\mathrm{t})$ los valores de la primera y última columna de la tabla 8, se obtiene en el gráfico de la figura 2 la ecuación de la línea recta: $y=0,5773 x+$ 0,9566. Esta ecuación permite calcular los TRH presentados en la tabla 9, según los LMP del DS-004-2017-MINAM2 para la reutilización del agua en riego de vegetales no restringido y restringido.

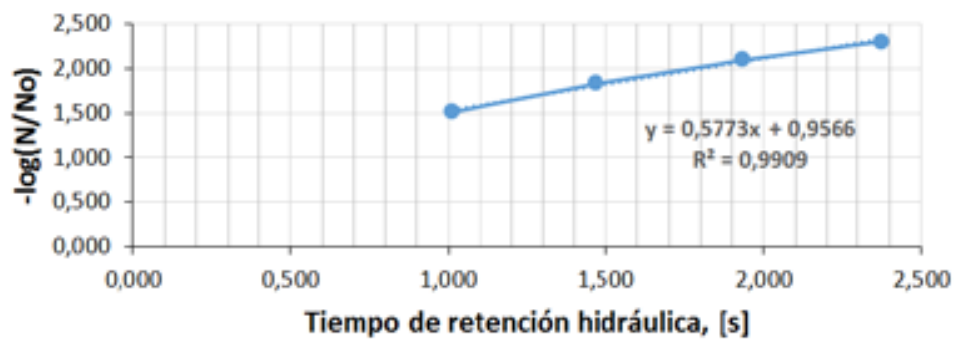

Figura 2. Gráfico de - $\log (\mathrm{N} / \mathrm{N} 0)$ versus los TRH, desinfección UV tipo de ensayo 2. 
Tabla 9. TRH de inactivación de coliformes fecales, riego de vegetales, ensayo tipo 2

\begin{tabular}{|c|c|c|}
\hline \multicolumn{3}{|c|}{ Ecuación de la línea recta, figura 3: $y=0,5773 x+0,9566$} \\
\hline $\begin{array}{l}\text { Coliformes fecales } \\
\text { sobrevivientes }^{3}\end{array}$ & $\begin{array}{c}\text { Riego de } \\
\text { vegetales }\end{array}$ & $\begin{array}{l}\text { TRH de inactivación de } \\
\text { coliformes fecales, [s] }\end{array}$ \\
\hline Inactivación total $1 \mathrm{NMP} / 100 \mathrm{ml}$ & -- & 7,49 \\
\hline $1000 \mathrm{NMP} / 100 \mathrm{ml}$ & No restringido & 2,29 \\
\hline $2000 \mathrm{NMP} / 100 \mathrm{ml}$ & Restringido & 1,77 \\
\hline
\end{tabular}

El TRH o de exposición a la radiación UV para la eliminación total de coliformes fecales totales de 7,49 s, está muy cercano al TRH que presenta Solsana ${ }^{10}$, que indica que las exposiciones normales de microorganismos patógenos a la radiación UV están entre $10 \mathrm{a} 20 \mathrm{~s}$.

\section{Cinética de inactivación: dosis}

Espesor medio de la capa líquida $(\mathrm{x})$, entre el reactor y la lámpara $<$

Área de la pared interna del reactor en contacto con el líquido

$$
A_{\text {ireactor }}=\pi D_{\text {ireactor }} L=\pi 6,3 \mathrm{~cm} 30 \mathrm{~cm}=593,76 \mathrm{~cm}^{2}
$$

Área exterior de la lámpara del reactor en contacto con el líquido

Área media irradiada

$$
A_{\text {lámpara }}=\pi D_{\text {lámpara }} L=\pi 2,6 \mathrm{~cm} 30 \mathrm{~cm}=245,04 \mathrm{~cm}^{2}
$$

$$
A_{\text {Media }}=\frac{A_{i_{\text {reactor }}}+A_{\text {lámpara }}}{2}=\frac{593,76+245,04}{2}=419,40 \mathrm{~cm}^{2}
$$

Volumen del reactor $\quad V_{\text {reactor }}=775,89 \mathrm{~cm}^{3}$

Espesor de la capa líquida

Potencia efectiva radiación UV

$$
\begin{gathered}
V_{\text {reactor }}=A_{\text {Media }} x \\
\mathrm{x}=\frac{V_{\text {reactor }}}{A_{\text {Media }}}=\frac{775,89 \mathrm{~cm}^{3}}{419,40 \mathrm{~cm}^{2}}=1,85 \mathrm{~cm}
\end{gathered}
$$

$$
\text { Pot }_{\text {efectiva }}=\text { Potencia }_{\text {nominal }} \times \text { rendimiento }=17 \times 0,65=11,05 \mathrm{~W}
$$

Intensidad de la fuente UV

$$
I_{0}=\frac{\text { Pot }_{\text {efectiva }}}{A_{\text {lámpara }}}=\frac{11,05}{245,04}=0,0451 \frac{\mathrm{W}}{\mathrm{cm}^{2}}
$$


Coeficiente de absorbancia

$$
\begin{aligned}
& \alpha=2,302585 \times A=2,302585 \times 0,284=0,654 \mathrm{~cm}^{-1} \\
& \mathrm{~A}=\text { absorbancia, }\left[\mathrm{cm}^{-1}\right]
\end{aligned}
$$

Intensidad a través de la capa de agua

$$
I=I_{0} e^{-\propto x}=0,0451 x e^{-0,654 x 1,85}=0,01345 \frac{W}{c m^{2}}
$$

Dosis de inactivación

$$
\mathrm{D}=\mathrm{I} \times \mathrm{TRH}
$$

$$
\begin{aligned}
& \mathrm{D}=\text { Dosis, }\left[\mathrm{J} / \mathrm{m}^{2}\right] \\
& \mathrm{I}=\text { intensidad } \mathrm{UV},\left[\mathrm{W} / \mathrm{m}^{2}\right] \\
& \mathrm{t}=\text { tiempo de exposición de la radiación, TRH, }[\mathrm{s}]
\end{aligned}
$$

El modelo matemático de la ley de Chick-Watson presenta la siguiente ecuación matemática para calcular la dosis de inactivación para microorganismos: $-\log \left(\mathrm{N} / \mathrm{N}_{0}\right)=\mathrm{k} / 2,302585 \mathrm{D}$. La tercera columna en la tabla 10 muestra las dosis de inactivación para coliformes fecales, ensayo tipo 2 .

Tabla 10. Dosis de inactivación de coliformes fecales, desinfección UV, ensayo tipo 2

\begin{tabular}{cccc}
\hline TRH, [s] & $\mathrm{I},\left[\mathrm{W} / \mathrm{cm}^{2}\right]$ & Dosis, $\left[\mathrm{W}-\mathrm{s} / \mathrm{cm}^{2}\right]$ & $-\log (\mathrm{N} / \mathrm{No})$ \\
\hline 1,011 & 0,01345 & 0,01360 & 1,511 \\
1,467 & 0,01345 & 0,01973 & 1,836 \\
1,936 & 0,01345 & 0,02603 & 2,098 \\
2,377 & 0,01345 & 0,03197 & 2,302
\end{tabular}

Los resultados de la tercera y cuarta columna de la tabla 10 fueron graficados, obteniéndose la figura 3. La línea recta y su ecuación permiten determinar las dosis respectivas para la eliminación de microorganismos tanto para riego de vegetales no restringidos y restringidos de acuerdo al LMP del DS-004-2017-MINAM².

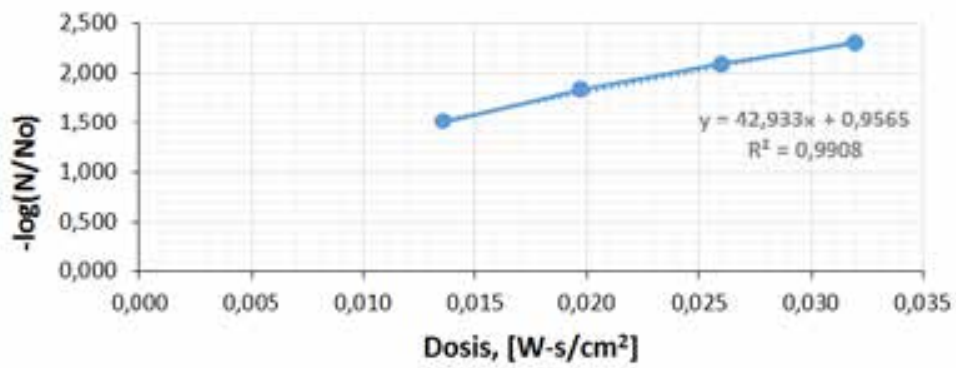

Figura 3. Gráfico de $-\log (\mathrm{N} / \mathrm{N} 0)$ versus dosis, desinfección UV ensayo tipo 2 
La tabla 11 muestra las dosis determinadas con la ecuación obtenida en la figura 4, dosis necesarias para la desactivación de coliformes fecales para LMP que indica el DS-004-2017MINAM2 en la reutilización del agua para riego de vegetales.

Según Solsana ${ }^{10}$ la dosificación de la radiación ultravioleta requerida para destruir los microorganismos más comunes, coliformes, Pseudomonas y otros, varía entre 6000 y 10000 $\mu \mathrm{W}-\mathrm{s} / \mathrm{cm}^{2}$ y las normas para la dosificación de radiación UV en diferentes países varían entre 16000 y $38000 \mu \mathrm{W}-\mathrm{s} / \mathrm{cm}^{2}$, si se comparan estos valores con los obtenidos en la tabla 11 , están dentro de la premisa de Solsana.

Tabla 11. Dosis necesaria en la inactivación de coliformes fecales, desinfección UV ensayo tipo 2

\begin{tabular}{|c|c|c|c|}
\hline \multicolumn{4}{|c|}{ Ecuación de la línea recta, figura $4: y=42,933 x+0,9565$} \\
\hline \multirow{2}{*}{$\begin{array}{l}\text { Coliformes fecales } \\
\text { Sobrevivientes }^{2}\end{array}$} & \multirow{2}{*}{$\begin{array}{l}\text { Riego de } \\
\text { vegetales }\end{array}$} & \multicolumn{2}{|c|}{$\begin{array}{l}\text { Dosis de inactivación de } \\
\text { coliformes fecales, [s] }\end{array}$} \\
\hline & & {$\left[\mathrm{W}-\mathrm{s} / \mathrm{cm}^{2}\right]$} & $\begin{array}{l}{[\mu \mathrm{W}-} \\
\left.\mathrm{s} / \mathrm{cm}^{2}\right]\end{array}$ \\
\hline Inactivación total $1 \mathrm{NMP} / 100 \mathrm{ml}$ & -- & 0,1006847 & 100684,7 \\
\hline $1000 \mathrm{NMP} / 100 \mathrm{ml}$ & No restringido & 0,0308083 & 30808,3 \\
\hline $2000 \mathrm{NMP} / 100 \mathrm{ml}$ & Restringido & 0,0237967 & 23796,7 \\
\hline
\end{tabular}

Finalmente, de acuerdo con los resultados obtenido en la desinfección UV ensayo tipo 2, se concluye que el agua desinfectada por este método puede ser usada para riego agrícola sin restricciones, debido a la baja carga microbiana de las mismas, 949 NMP de coliformes fecales en $100 \mathrm{ml}$, parámetro que está por debajo de los LMP establecidos por el D.S. 004-2017-MINAM ${ }^{2}$ para aguas categoría 3, riego de vegetales no restringido y restringido y bebidas de animales.

\section{CONCLUSIONES}

La prueba de desinfección UV, del efluente secundario tal como se obtiene en la planta Totora no alcanzó la calidad sanitaria para riego de vegetales no restringidos y restringidos, toda vez que solamente se llegó a $20323 \mathrm{NMP} / 100 \mathrm{ml}$ de coliformes fecales sobrevivientes, valor distante de los LMP del DS-004-2017-MINAM² que indica 1000 y 2000 NMP/100 ml.

El proceso de desinfección UV del efluente secundario previamente tratada con procesos terciarios de filtración y adsorción alcanzó la calidad sanitaria que exige los LMP del DS-0042017-MINAM ${ }^{2}$ para 1000 y $2000 \mathrm{NMP} / 100 \mathrm{ml}$ de coliformes fecales sobrevivientes con 2,29 y 1,77 s de tiempo de residencia y 30808,3 y $23796,7 \mu \mathrm{W}$-s/cm 2 de dosis de inactivación, para agua de riego de vegetales de tallo bajo y alto respectivamente, concluyendo que este proceso de desinfección UV es eficiente para la reutilización del agua para riego agrícola sin restricciones. 
Finalmente, se concluye que el estudio de investigación del proceso de desinfección mediante radiación UV del efluente secundario de la PTAR Totora es una alternativa de solución para la inactivación de los microorganismos patógenos y mejorar la calidad de agua para riego de vegetales de tallo corto y alto sin restricciones, siempre en cuando se realice los procesos de tratamiento terciario de filtración y adsorción antes de la desinfección UV.

\section{AGRADECIMIENTO}

Los autores agradecen a la Planta de Tratamiento Agua Residual Totora de Ayacucho y a la Universidad Nacional de San Cristóbal de Huamanga por las facilidades prestadas en el desarrollo de la investigación en sus instalaciones.

\section{REFRERENCIAS BIBLIOGRÁFICAS}

1. MINAM. Decreto supremo $\mathrm{N}^{\circ}$ 003-2010-MINAM. Límites máximos permisibles para efluentes de tratamientos de aguas residuales domésticas o municipales. [Internet] Lima: Diario Oficial El Peruano; 2010. [Citado 12 oct 2017]. Disponible en: http://www. minam.gob.pe/disposiciones/decreto-supremo-n-003-2010-minam/

2. MINAM. Decreto supremo $N^{\circ}$ 004-2017-MINAM. Estándares de calidad ambiental (ECA) para agua, Anexo categoría 3: riego de vegetales y bebidas de animales. [Internet] Lima: Diario Oficial El Peruano; 2010. [Citado 25 set 2017]. Disponible en: http://www. minam.gob.pe/disposiciones/decreto-supremo-n-004-2017-minam/

3. Tarrán EP. Desinfección por Luz Ultravioleta. [Internet]. São Paulo; 2004 [Citado 12 de abril de 2015]. Disponible en: https://es.scribd.com/document/51327083/Desinfeccionpor-luz-ultravioleta

4. Rodrigues P. Desinfecção de efluentes de sistemas de tratamentos de esgotos sanitários por meio da radiação ultravioleta. [Tesis de maestría]. São Paulo: Universidade de São Paulo; 1995 [Citado 23 jul 2015] Disponible en: http://pelicano.ipen.br/PosG30/ TextoCompleto/Paulo\%20Rogerio\%20Rodrigues\%20Camacho_M.pdf

5. Divino D. Utilização da radiação ultravioleta como fonte allternativa para desinfecção de piscinas de hidroterapia em ambiente fechado. [Tesis de maestría]. Ribeirão Preto: Universidade de Ribeirão Preto; 2007 [Citado 16 abril 2015] Disponible en: http://www. unaerp.br/documentos/265-denis-divino-lara/file

6. Vargas G. Tratamiento terciario de esgoto sanitário através de processos oxidativos avançados para obtenção de aguas de reuso. [Tesis de doctorado]. Santa Catarina: Universidade de Santa Catarina; 2008 [Citado 23 jul 2015] Disponible en: https:// repositorio.ufsc.br/xmlui/handle/123456789/91782

7. Dos Santos T, de Souza T. Avaliação da eficiência da aplicação de radiação UV na inativação de coliformes totais e Escherichia coli na ETE do Sucuri - Cuiabá/MT. Engenhaaria Ambiental. 2009; 6(3): 383-394. 
8. EPA: Environmental Protection Agency. Folleto informativo de tecnología de aguas residuales, Desinfección con luz ultravioleta. [Internet] EPA. 832-F-99-064; 1999. [Citado 20 jun 2015]. Disponible en: https://www.epa.gov/sites/production/ files/2015-06/documents/cs-99-064.pdf

9. Franci R. Desinfecção de efluentes sanitários. $1^{\text {a }}$ Ed. Vitoria: ABES; 2003. p 214.

10. Solsona F, Méndez J. Desinfección del agua. Lima: Centro Panamericano de Ingeniería Sanitaria y Ciencias del Ambiente, Organización Panamericana de la Salud y Organización Mundial de la Salud; 2007. p 94. 